\title{
Note from the editors on temperature compensated CMOS ring VCO for MEMS gas sensor
}

The article titled "Temperature compensated CMOS ring VCO for MEMS gas sensor" by Jamel Nebhen, Stéphane Meillère, Mohamed Masmoudi, Jean-Luc Seguin, Hervé Barthelemy, Khalifa Aguir was inadvertently published in the regular issue Volume 76 Issue 2 (instead of the Special Issue "NEWCAS 2012", where it was originally scheduled to appear).
Therefore, the article has been notified with this note that it is one of the papers in the Special Issue: NEWCAS 2012.

The original article can be found at doi:10.1007/s10470013-0095-x 